\title{
LOS ROSTROS Y LAS HUELLAS DEL JUEGO ${ }^{1}$ THE FACES AND THE FINGERPRINTS OF PLAY
}

La investigación se desarrolla en el programa de educación infantil de la Universidad Pedagógica Nacional y pretende identificar, comprender y reflexionar sobre las creencias de ocho profesoras de dos Jardines Infantiles de Secretaría de Integración Social (SDIS) cuyo horizonte pedagógico es el trabajo en inclusión social. Este es un estudio de carácter cualitativo, que profundiza en un caso para darle prioridad a lo que dicen y hacen las docentes en su práctica cotidiana. Se utilizaron instrumentos para la recolección de la información como registro en vídeo, entrevistas y talleres de devolución. Los resultados conducen, entre otras, a las siguientes conclusiones: las creencias sobre juego que hoy tienen las maestras están permeadas por las experiencias, interacciones, y contextos de infancia.

Palabras clave: educación inicial, creencias, juego, inclusión.

Abstract

This paper presents the research conducted in the Early Childhood Education program of the Pedagogic National University, intended to identify, understand and to think about the beliefs of eight teachers of two Infantile Gardens of the Secretariat of Social Integration (SDIS), whose pedagogic horizon is working for social incorporation. This is a mainly qualitative work, which explores a case, prioritizing what the teachers say and do in their daily practice. Instruments for compiling the information were used, such as video - recording, interviews and feedback workshops; the results lead to the following conclusions, among others: the teachers' beliefs about play that today, are influenced by experiences, interactions, and childhood contexts. .

Keywords: Early Childhood Education, beliefs, play, inclusion.

Fecha de recepción: 21 de junio de 2011

Fecha de aprobación: 17 de octubre de 2011

1 Proyecto de investigación elaborado en el marco de la tesis doctoral de la profesora Sandra Marcela Durán. Doctorado en Pedagogía Social. Universidad de Granada, España, titulado Creencias sobre el juego en la práctica docente del profesorado en dos Centros Infantiles de la Secretaría de Integración Social (SDIS) en Bogotá- Colombia y del proyecto de investigación: Creencias sobre juego de ocho profesoras de dos Jardines Infantiles de Secretaría de Integración Social (SDIS), que tienen como horizonte pedagógico el trabajo en inclusión social fase II del proyecto DSI 219-10. Equipo de investigación: Coinvestigadoras: Consuelo Martín Cardinal, Jenny Pulido. Monitoras: Luisa Castillo Restrepo, Mónica Gil Cardona 2 Docente Investigadora Universidad Pedagógica Nacional. Magister en Educación. Candidata a Doctor en Pedagogía Social. Universidad de Granada, España. Correo electrónico: sandydfer@hotmail.com 
Sustentadores del conflicto en el ámbito escolar

Esta investigación se propone identificar, comprender y reflexionar sobre las creencias del profesorado respecto al juego y la acción misma de jugar con niños de 0 a 2 años, a partir de tres intenciones: primera, la indagación sobre la práctica y el discurso de ocho maestras de dos Jardines de la Secretaría de Integración Social y sus creencias sobre el juego; segunda, el reconocimiento del rol del docente, el papel que cumplen el ambiente y los objetos, y las distintas manifestaciones de juego que se pueden identificar en los niños desde cada contexto; y tercera, la posibilidad de generar procesos de diálogo y reflexión alrededor de las creencias sobre el juego de las maestras, como oportunidades para (re)pensar la práctica docente.

Antes de abordar estos propósitos hay que hacer énfasis en que identificar y comprender las creencias de los maestros implica un acercamiento a su discurso y a su práctica. De esta manera, se encuentra el sentido de sus actuaciones y se transforma la enseñanza en una experiencia en la que sus actores, las maestras, interpretan la realidad y promueven saberes que permiten construir, reconstruir y tomar decisiones en y desde su labor pedagógica.

Para el cumplimiento de estas pretensiones se parte de un enfoque interaccionista, en el que se reconoce que trabajar con las creencias de las maestras es trabajar con su vida, su historia, con lo que las constituye como sujetos y profesionales. Así se busca establecer un diálogo con las ideas de las investigadoras, no para comparar, sino para reconocer nuestras propias diferencias, posturas y apuestas.

Explorar las creencias en esta investigación da la posibilidad de ir tras las huellas del pensamiento docente que se refleja en sus acciones; de ahí que se haya titularla Los rostros y las huellas del juego, ya que ese pensamiento tiene que ver con las comprensiones e interpretaciones con las cuales el profesor fundamenta su práctica cotidiana. Es necesario aclarar que dicho conocimiento no solo es fruto de las construcciones que él ha hecho durante su formación profesional, sino que además involucra su historia personal en diversos escenarios de su vida. Esto está relacionado con ese acumulado social y cultural que se representa en las creencias que determinan su acción y el sentido que él le otorga.

Para descubrir los rostros y las huellas del juego, es importante reconocer que en la "objetividad" del conocimiento, producida mediante metodologías cualitativas, no se alcanza al negar la subjetividad. Por el contrario, es explicitando las propias posturas, preguntas y tensiones como se alcanza un conocimiento objetivo de la realidad social, dado a través de la intersubjetividad como criterio de validación. Se puede afirmar entonces que en la investigación se generan diversas interpretaciones, que no tienen pretensiones de generalidad ni objetividad; no es un estudio experimental, ni de causalidad, ni de prueba de hipótesis. Lo que se pretende comprender lo es que sucede con las maestras respecto al juego desde sus creencias; en esta medida, se busca entender una situación social, reconociendo sus características y dinámicas particulares.

En este estudio cobra gran importancia el conocimiento de sentido común de los sujetos sociales, puesto que se incorporan las interpretaciones que los sujetos realizan para dar sentido a los fenómenos y otorgar significados a sus acciones. Por tanto, el enfoque metodológico en el que se enmarca este estudio es el hermenéutico interpretativo, que ha legitimado en el campo de la producción científica la importancia del lenguaje y los significados para comprender el sentido otorgado a un fenómeno social, a partir del contexto socio-histórico desde el cual se produce.

Recurrimos a la investigación narrativa como perspectiva específica de investigación educativa, puesto que guarda una estrecha relación con aquella fuerza que el enfoque hermenéutico- interpretativo da a la comprensión de los sentidos que los implicados en una investigación otorgan a una práctica social. Como plantea Bolívar (2002): "Contar las propias vivencias y "leer" (en el sentido de "interpretar") dichos, hechos y acciones, a la luz de las historias que los actores narran, se convierte en una perspectiva peculiar de investigación".( p.3)

Entonces, la investigación narrativa permite comprender los sentidos que las ocho maestras le otorgan a su trabajo en torno al juego y cómo actúan en sus contextos profesionales. El propósito es develar el conocimiento práctico o experiencial del profesorado captando la experiencia en formas narrativas, que permitan evidenciar sus interacciones con el contexto social y en un momento determinado.

La estrategia metodológica del proyecto es el Estudio de Caso, cuyo objetivo primordial es presentar la particularidad, más que la generalización. Se seleccionó este caso en particular y se llegó a conocerlo a profundidad para caracterizarlo en sí mismo, principalmente, más que para ver en qué se diferencia de los otros. 
Para identificar las creencias de las maestras sobre juego es fundamental observar sus prácticas. Por lo tanto, se les pidió su consentimiento para filmarlas, para luego iniciar el registro en vídeo durante media jornada en dos instituciones, para luego hacer un proceso de selección y transcripción de los fragmentos de juego.

El análisis interpretativo que se presenta a continuación muestra el primer acercamiento al sistema de creencias sobre el juego en niños y niñas que opera en cuatro profesoras de educación inicial. Cabe anotar que los hallazgos expuestos son el producto del trabajo con docentes de una de las dos instituciones seleccionadas.

La institución en la que se desarrolló esta investigación brinda a los niños y niñas de la primera infancia educación, nutrición y cuidado, en convenio con la Secretaría de Integración Social. Su misión es proveer calidad, innovación y cobertura en la educación de primera infancia en Colombia y su visión es de cambio social, pues pretende transformar el país a través del desarrollo del potencial de la primera infancia.

En este centro educativo cada uno reconoce y valora a los niños y niñas como seres únicos; a los educadores como personas que escuchan, observan, reflexionan y cuestionan para favorecer el desarrollo de la niñez y para mejorar sus propias prácticas pedagógicas; a las familias como invitadas a participar de manera activa de la experiencia de aprendizaje; al arte con sus principios y elementos como una dimensión fundamental del proceso de aprendizaje; a la creatividad como fin y medio para el desarrollo cognitivo y emocional de los niños y niñas; al juego como derecho y vehículo para explorar el mundo, encontrar respuestas, desarrollar estrategias y tomar decisiones; y al espacio físico como posibilitador del juego, la exploración, el asombro y la investigación, pues el ambiente debe ser estéticamente armonioso y reflejar las identidades de quienes lo habitan.

Para identificar las creencias es importante acercarse no sólo a las prácticas de los docentes, sino también a las razones que desde cada contexto socio-cultural se crean para fundamentar sus acciones. En consecuencia, se diseñaron entrevistas semi-estructuradas a partir de registros de secuencias de juego grabadas en vídeo, que permitieran comprender el actuar de las maestras así como los lugares anclados en sus historias de vida, desde los cuales estructuran su trabajo con niños y niñas.
Para los propósitos de este artículo, se exponen los fragmentos que muestran secuencias de juego extraídas de las prácticas de las maestras, las cuales fueron registradas en vídeo en jornadas de trabajo pedagógico, para luego ser puestas en diálogo con perspectivas antropológicas, psicológicas y educativas construidas en relación con el juego, las creencias y la inclusión social. En este orden de ideas, se presentan las primeras aproximaciones interpretativas respecto al sistema de creencias de las docentes.

\section{Institución uno}

\section{El poder de los objetos}

El papel de los objetos en el juego es una cuestión que ha tomado gran fuerza en la investigación, pues tiene que ver no sólo con el objeto por sí mismo, sino especialmente con quienes lo diseñan y con su intencionalidad. Además, el asunto de los objetos implica pensar en la exploración y las interacciones que a partir de ellos se suscitan. Por tanto, el poder de los objetos en el juego es el foco del análisis que se presenta a continuación.

Todo comienza cuando Silvia, la maestra, toma un par de sonajeros hechos a mano, (un par de latas selladas con semillas adentro). Estos materiales son elaborados por las maestras para los niños y responden, por un lado, a las observaciones que ellas hacen de lo que les interesa a los pequeños, y por otro, a lo que se puede generar dentro de un proceso de exploración, que lleva a los niños y las niñas a descubrir con sus sentidos ciertos fenómenos.

Los sonajeros escogidos por Silvia son ubicados en el piso, sobre el tapete, uno cerca de ella y el otro frente a Pablo, un poco alejado, al parecer con la intención de lograr que Pablo se arrastre hacia adelante y lo tome.

La maestra espera pacientemente por un rato $y$, al ver que Pablo no se desplaza, hace rodar el sonajero despacio hacía el bebé. Él lo toma con una de sus manos e inmediatamente lo agita para hacerlo sonar, mientras mueve su cabeza y sonríe, mostrando gusto por el sonido que se produce. Está acción se repite varias veces.

Silvia, quien lo observa y quiere ser parte de este momento, toma el otro sonajero y lo hace sonar también, mientras le dice con una gran sonrisa: “¡eso, muy bien!”. En sus miradas se revela la conexión que se produce entre 
ellos en ese momento; sobran las palabras para hacer acuerdos y es el lenguaje corporal el que invita hacer sonar las latas al tiempo y a sumergirse en el mundo del sonido.

Esto hace pensar en la importancia de los objetos sencillos y cotidianos, como juguetes que dan lugar a exploraciones e interacciones que se vuelven complejas por el placer que producen a sus protagonistas y por la comunicación que se suscita entre ellos. En ocasiones, nos dejamos llevar por aquellos juguetes fabricados que circulan en el mercado, pero en realidad no dicen nada a quien los manipula, ya sea por que no despiertan interés, o porque son tan elaborados, tan mecánicamente resueltos, que la acción de los niños se limita a oprimir un botón y esperar a ver qué ocurre. Esto indudablemente convierte a niños y niñas en observadores pasivos de un sistema atractivo en principio, pero rutinario en sí mismo.

Al respecto, Garvey (1983) manifiesta, desde una mirada psicológica que va más allá del objeto comercializado e industrializado, que dentro de esta categoría de juguetes pueden entrar otros objetos con los cuales el niño/a también se expresa, interactúa y explora, y que bien pueden ser naturales, como hojas secas, semillas, o industriales como espejos, collares, llaves, etc. Frente a ello, valdría la pena interrogar por el lugar del juguete en la vida de niños y niñas, pues ¿qué lo hace juguete? ¿Es la intención que persigue un adulto? ¿O quizá la acción que imprime un niño sobre el objeto? En este caso, la maestra reconoce el juguete como tal en tanto le posibilita al niño un sinnúmero de experiencias que enriquecen no solamente su pensamiento, sino también su actuar lúdico en el entorno.

En un escenario económico y político como el actual, el interés por mercantilizar y regular la vida de los sujetos desde el consumo ha permeado incluso el juego. Éste, a pesar de haber sido definido por diversos sociólogos y antropólogos como improductivo y gratuito, ha ingresado progresivamente a la lógica del mercado a través del juguete. Sin embargo, las maestras con quienes se realizó esta investigación, evidenciaron un distanciamiento frente a dicha lógica en tanto los juguetes propuestos son, como lo expresa Garvey, objetos cercanos a la cotidianidad en la que el niño puede decidir qué jugar y cómo jugar. En el juego espontáneo, todo puede ser ocasión y compañero de juego; el mundo que rodea al niño se convierte en juego: un trozo de tela, una caja, un pedazo de papel, una piedra, el agua, etc. Se suele encontrar a los niños de 0 a 2 años más frecuentemente con objetos sencillos y simples, porque estos les permiten imaginar y crear tantas cosas como se le ocurren.

\section{El rol del maestro es determinante en el juego}

Hablar del lugar del cuerpo en el juego implica pensar el cuerpo como lenguaje, como un cuerpo que expresa y comunica. Este es precisamente el asunto que se expone en la siguiente situación, en donde se podrá evidenciar al maestro que escucha y observa con atención las acciones de los niños y las niñas. Es el maestro que pregunta y descubre, en el lenguaje corporal, posibilidades para jugar.

Pablo, quien está acostado boca abajo, comienza a mover su cabeza de arriba hacia abajo y a flexionar y estirar sus piernas, mientras sonríe y mira a Silvia, su maestra, quien se acuesta también boca abajo y avanza hacia él imitando los movimientos de su cabeza, asintiendo y diciendo repetidas veces "sí". Al verla, Pablo encuentra esta respuesta y la mira complacido.

Lo anterior se repite hasta que Silvia empieza a mover la cabeza como haciendo una seña de negación, mientras repite "no, no, no". Pablo detiene su movimiento y se queda mirándola; ella, al no encontrar respuesta vuelve asentir con la cabeza, a lo que él responde imitándola, enérgico y sonriente. Pablo repite varias veces este movimiento, pues parece causarle mucho placer, y al encontrar en su maestra ese otro que lo imita, descubre mayores sensaciones que quiere seguir experimentando.

La maestra, al ver que Pablo quiere continuar con este pequeño juego, entona una canción para acompañar los movimientos: "mi cabecita dice sí, mi cabecita dice no, no, no, si, si, si, no, no, no". Mientras esto ocurre, Pablo la mira atento y sonriendo, pero sin hacer ningún movimiento.

La maestra, motivada por aquella sonrisa, continúa la canción, pero ahora saca su dedo y lo mueve de acuerdo a lo que dice la canción: "mi dedito dice si, mi dedito dice si, si, si, no, no, no". En ese momento sucede algo extraordinario: cuando la maestra mueve el dedo y dice sí, Pablo enérgicamente asiente con su cabeza.

Luego Silvia dice (moviéndose) "la cabeza" y repite: "mi cabeza dice sí, si si, no, no...", pero al ver que Pablo no deja de asentir, ella deja de decir "no" y vuelve a decir "sí". Entonces acaricia con una mano a Pablo, quien mueve encantado su cabeza y exagera el movimiento cuando encuentra la complicidad de su maestra que lo sigue imitándolo. 
Luego, la maestra se sienta y comienza a acercarse y alejarse; cuando se aleja dice "sí, sí, sí" y cuando vuelve a estar cerca se queda inmóvil. Mientras tanto, Pablo la mira sonriendo y mueve la cabeza asintiendo.

El acompañamiento del maestro, desde su ser corporal, es fundamental para potenciar y enriquecer los momentos de juego de los niños y niñas. Muy seguramente, si Pablo hubiese estado sólo y sin interlocución alguna, esta secuencia no hubiese sido posible; se necesita de otro que proponga, que espere su turno, que desee que el otro continúe las acciones, que encuentre en el cuerpo del otro un potencial afectivo para dar rienda suelta a la generación de vínculos, risas y complicidad en el juego.

En este sentido, Sarlé (2006), desde un enfoque educativo, manifiesta que:

La participación del maestro en el juego asume la forma de un degradé. En un extremo de este continuo, el educador sólo contempla el juego de los niños; en el otro, interviene tanto que se diluye, pierde su forma o deja de ser lo importante. Entre estos dos polos aparece tímidamente una tercera modalidad en la que el educador enriquece el juego de los niños, le otorga nuevos contenidos y potencia la aparición de nuevos juegos. (p.132)

La implicación corporal que se establece entre la maestra y el niño, desencadena diálogos que posibilitan la construcción de diferentes juegos, y obedece a la observación de la maestra, a su interés por reconocer y potenciar la acción lúdica del bebé. El acompañamiento en el juego, obedece, por una parte, a las creencias que sobre él tiene la maestra, para quien observar y ser parte activa es fundamental para conocer al otro como un sujeto de la corporalidad que propone movimientos, desplazamientos y posturas que ofrecen nuevas estructuras al juego. Por otra parte, ese legado anclado en su historia de vida, en el cual se destacan los juegos infantiles en los que estaba acompañada por otro, se constituyen en el lugar de partida y proyección de sus creencias.

\section{El ambiente: un dispositivo para el juego}

El ambiente en esta institución cumple un papel fundamental, pues se inspira en la filosofía de Reggio Emilia, la cual lo privilegia y cataloga como el tercer profesor; el ambiente es el mensaje, puesto que comunica mediante de la disposición de los objetos y la intencionalidad de quien lo organiza.
Esto es claro para las maestras, quienes en el proceso de conocimiento y recontextualización de esta metodología en la institución, son conscientes de que uno de los roles del maestro es diseñar ambientes que provoquen, insinúen e inviten a tener experiencias únicas en interacción con el entorno, el material, sus pares y el profesorado.

A este respecto, Cano y Lledó (1997), desde un enfoque ecológico, expresan que:

Los espacios donde desarrollamos nuestra vida, donde sentimos, conocemos, y donde nos movemos, donde nos comportamos y pensamos, no funcionan como meros "decorados" o como "telones de fondo" - estáticos- de nuestra actividad humana. Los entornos/espacios, ya sean naturales (casi siempre humanizados) o más frecuentemente construidos, actúan a través de sus propias características y estímulos y, de acuerdo a las interacciones sociales que ellos producen, conforman, aunque no determinan, el comportamiento de las personas. El entorno, los espacios, jamás son neutros. (p.12)

Para ilustrar esto, recurrimos a la maestra Carolina, quien prepara el ambiente para comenzar la experiencia del día. Lo primero que hace es despejar el espacio y acomodar unos pliegos de papel celofán de colores en un rincón cubierto con varias colchonetas. Luego ubica cada pliego de papel de manera que quede uno muy cerca del otro, quizás porque lo que pretende es que los niños/as se acomoden muy cerca del material, para así comenzar la exploración y provocar interacciones entre los pequeños.

Una vez termina de preparar el ambiente, la maestra Silvia levanta a Pablo -quien tiene un sonajero en la mano - y a Mónica, los toma en sus brazos y los lleva a las colchonetas en donde está dispuesto el papel. Luego, los acuesta boca abajo en las colchonetas al frente de los pliegos de colores de papel celofán y se ubica a un lado de las colchonetas, en un lugar manera estratégico desde el cual puede observar lo que sucede en el ambiente diseñado. Parece buscar una perspectiva panorámica de las interacciones que surjan entre los niños/as y los objetos dispuestos.

De repente, Pablo toma un papel y lo agita con su mano, haciéndolo sonar una y otra vez. Por momentos se distrae con el sonajero que aún tiene en la mano, pero sigue moviendo el papel; parece intentar hacer sonar el sonajero y el papel al tiempo, sin lograrlo. La maestra Silvia lo observa y le pregunta a Pablo si le gusta el papel, 
mientras Carolina, la otra maestra del grupo, toma un cuaderno y hace algunas anotaciones (al parecer sobre lo que está sucediendo en la experiencia con el papel). una vez termina de escribir, se levanta y pone en la grabadora el CD de Mozart, un dispositivo que muy seguramente ella sabe, es clave en la experiencia y en el ambiente mismo.

A continuación, vuelve a donde están los niños, se arrodilla y se inclina hacia Pablo y con sus manos le pega a las colchonetas, primero con una mano y luego con la otra, como pretendiendo llamar la atención de este pequeño, y lo logra, pues sus movimientos no sólo generan un sonido muy particular en las colchonetas, sino también en el papel. Pablo sigue con la cabeza sus movimientos y Carolina deja ver en su rostro la satisfacción de que así sea, instantes después, Carolina pasa la mano sobre el papel, haciéndolo sonar de un modo diferente y allí ocurre algo muy interesante: cuando ella deja de hacerlo, Pablo asiente con la cabeza, por lo que Carolina comenta con entusiasmo “¿sí le parece?”, Pablo continua moviendo el papel, pues también como su maestra, quiere hacerlo sonar y al lograrlo, escucha extasiado su sonido.

Luego Carolina, como queriendo mostrar otras opciones a los niños y niñas, toma un pliego de papel que está extendido, pero que no está siendo manipulado por nadie y lo pone encima de Pablo, cubriéndolo. Él, debajo del papel, continua moviendo la cabeza como diciéndole a su maestra que disfruta de lo que ella le propone y como queriendo saber lo que ocurrirá después. Carolina se recuesta sobre la colchoneta, de modo que su cabeza quede a la altura de la de Pablo y levanta el papel, introduce su cabeza y le habla, lo vuelve a bajar y le pregunta a Pablo: “dónde está?”. Esta acción se repite varias veces y mientras lo hace, Pablo mueve su cuerpo emocionado. Después de hacer esto por un tiempo más o menos prolongado, Carolina toma el papel y lo que hace ahora es ponerlo y quitarlo enfrente de su cara.

Mientras tanto, Silvia se arrodilla enfrente de Mónica y comienza hacer lo mismo que observa en su colega Carolina: la cubre con el papel y la descubre, le dice "hola", y repite la secuencia. Aparte del saludo cada vez que la descubre, a veces también le habla a través del papel preguntándole “¿quién está por allá?”.

El juego anterior invita a pensar en Bruner (1984), quien desde una mirada psicológica, hace una impecable reflexión en torno a los juegos del cu-cú:
El formato del juego puede ser concebido, como si tuviera una "estructura profunda" y un conjunto de reglas de realización con las cuales se maneja la superficie del juego. La estructura profunda del cu-cú es la desaparición y reaparición controlada de un objeto o de una persona, la estructura superficial puede ser construida con el uso de pantallas, vestidos o chucherías, variando el tiempo y la acción entre la desaparición y la aparición, variando los enunciados que se usan, variando qué o quién se va a desaparecer... $(\mathrm{p}, 46)$

De este ambiente provocador, colmado de interacciones, surge un juego de escondite muy interesante, pues contiene una gran riqueza de secuencias comunicativas en las cuales el bebé, una vez tiene clara la acción que lidera la maestra, la comprende y la maneja, y es capaz de liderar este juego con gran habilidad y de proponer y descubrir nuevas formas de jugarlo.

Los juegos de escondite requieren de la complicidad de sus participantes, de la ficción de la maestra, de su capacidad simbólica, de su convicción por crear una realidad distinta en un escenario habitual. Exigen también objetos ubicados estratégicamente en un ambiente planificado para generar relaciones placenteras, cargadas de una gran intencionalidad comunicativa que movilizan todas las secuencias lingüísticas, pero también vínculos afectivos que tejen una serie de relaciones de las cuales, sin lugar a dudas, las maestras de esta institución son las más convencidas.

\section{La imitación en el juego}

La imitación en el juego cumple un papel primordial, puesto que es el proceso por el cual se llegan a conocer a fondo ciertos fenómenos de la vida cotidiana y adaptarse a ellos (ser madre, profesora, médico, etc.). Además, el juego y la imitación comparten el placer, una característica esencial, por lo que es posible decir que los bebés disfrutan la acción de imitar.

La imitación ayuda a reinventar los objetos y a elaborar nuevos significados; por ejemplo, el niño que hace torres con fichas de construcción imitando a su madre o profesora, más adelante puede construir naves, carros, aviones y muñecos. Vigotsky (1933), desde un enfoque psicológico, manifiesta que la imitación es una regla interna de todo juego de representación. Mediante ella, el niño se apropia del sentido socio-cultural de toda actividad humana ( $\mathrm{p}$ 162). 
Ello se evidencia cuando Pablo está en frente de un canasto lleno de fichas de construcción y de repente se encuentra un carro y comienza a pegarle contra el piso. Al observarlo detenidamente, la maestra se aproxima a él y se sienta muy cerca de Pablo (quien ahora tiene el carro en la boca) una vez se acomoda le dice "¿está bueno?". Entonces se inclina hacia él, toma un carro, empieza a moverlo de un lado hacia el otro, deslizándolo, haciendo el sonido y pitando. Pablo la mira sonriendo, aunque sigue con el carro en la boca.

Cuando lo saca de la boca, la maestra le dice "eso, póngalo a rodar", mientras sigue haciendo el sonido del carro y pitando. A continuación, tras observar lo que su maestra hace una y otra vez, Pablo levanta el carro y lo mueve cerca a la mano de Silvia; ella lo toma y le dice "gracias", lo pone lejos de él y se lo lanza cuidadosamente, haciéndolo rodar hacia donde él está; él lo toma, le pega con la mano y vuelve a moverlo cerca a la mano de Silvia, seguramente esperando que ella repita esta acción. Puede destacarse que los niños y niñas son los protagonistas de su propio aprendizaje, pues logran una interacción social y exploran sus temas de interés.

Él sigue moviendo el carro y por momentos, mientras el carro queda en el piso, ella lo empuja. haciéndolo rodar. Luego le pregunta a Pablo “ ¿cómo hace el carro?” y vuelve a hacer el sonido; él la mira sonriente, así que ella toma otro carro que está cerca a los pies de Pablo y dice, con tono entusiasta, "mire, por aquí hay otro más grande". mientras lo coge, lo pone en el piso y lo pone a rodar en frente de Pablo, mientras ella continúa haciendo el sonido. Cuando el carro llega a donde él se encuentra, lo toma con sus manos, mientras Silvia vuelve a tomar el primer carro y se lo lanza rodando; cuando él lo toma, ella toma el otro y lo hace rodar. Esto se repite varias veces, y una de ellas comentan; "uy, se estrelló". Entonces, Pablo toma el carro más grande y lo mueve de un lado a otro, y de arriba abajo; de repente, se queda mirándolo y realiza un sonido imitando el que Silvia realizaba cuando lo ponía a andar.

Así, la imitación en los bebés se constituye en el lugar de placer que involucra a otros y también en el mecanismo de interacción con el entorno. Además, como plantea Vigotsky (1933),

...durante el juego, los niños se proyectan en las actividades adultas de su cultura y recitan sus futuros papeles y valores. De este modo, el juego va por delante del desarrollo, ya que así los niños comienzan a adquirir motivación, capacidad y actitudes necesarias para su participación social, que únicamente puede llevarse a cabo de forma completa con la ayuda de sus mayores y sus semejantes (p.162).

Aquella maestra que juega con el carro quizás es consciente de la importancia de la imitación en el juego. Es posible que en sus juegos de niñez, imitara a las personas que estaban a su alrededor o evocara situaciones proyectando lo acontecido en ellas. Podría afirmarse que cuando la maestra le otorga relevancia especial al juego del bebé, es porque ha construido la creencia de que imitar va más allá de una acción fisiológica, e implica una tarea que moviliza estructuras de pensamiento en las que el niño comprende fenómenos de la vida cotidiana.

\section{El papel de la exploración en el juego}

La exploración es un proceso que se destaca dentro del juego con los bebés, puesto que es la manera como conocen el entorno, a los otros y a sí mismos por medio de los sentidos. Esta exploración a profundidad de los objetos es muy importante, porque a partir de ello llega a otorgar otros significados a los objetos, lo cual es primordial dentro del juego.

Los sentidos cumplen un papel fundamental en todo este proceso de exploración, aunque no son lo único que lo implica, pues de este proceso también hacen parte la riqueza de las interacciones, las posibilidades del espacio, los objetos, entre otros. El trabajo alrededor de los sentidos sí es esencial, incluso para las maestras; la exploración podría asumirse como juego. Esto se evidencia con lo acontecido en el nivel de materno dos, en el que se diseñan experiencias sensoriales como la esencia del trabajo con los bebés.

Para el día de la grabación, las maestras han planeado disponer harina de trigo sobre colchonetas, así que lo primero que hacen es quitarle la ropa a los niños para que queden únicamente en pañal. Una vez están sin ropa, una de ellas toma puñados de harina y los distribuye en pequeñas montañas por la superficie de las colchonetas. Al finalizar, sale del lugar y espera, sin decir nada, a que los niños se percaten de lo que ella acaba de disponer y de manera libre se acerquen al lugar.

José es el primero en acercarse. Toma con sus manos la harina, la observa detenidamente y luego abre su mano, dejándola caer un poco sobre las colchonetas. Después la prueba, introduciéndola a su boca hasta cierto punto; luego esparce la harina con sus manos, 
moviéndolas de un lado hacia el otro y observando detenidamente lo que ocurre. Luego decide gatear sobre la harina esparcida, se desplaza y vuelve a observar lo sucedido; parece preguntarse cuál es el efecto de su cuerpo en movimiento sobre este material y evidencia con su postura y sus gestos. Está muy interesado en lo que descubre y por ello repite la acción varias veces.

Lo sucedido es muy interesante, pues ilustra el fenómeno de la exploración, que según Garvey (1983) se evidencia cuando un objeto o juguete no es familiar para el niño o la niña y, por ende, tiende a establecer una cadena de exploración, familiarización y eventual entendimiento. Esta secuencia, que se repite con frecuencia, conduce a conceptos más maduros acerca de las propiedades físicas (tamaño, textura, forma) de los objetos.

Este momento causa gran impacto en Bibiana, la maestra, quien toma una cámara fotográfica para registrar lo que sucede con los bebés. Mientras tanto, Susana llega al lugar y se acerca sigilosa. Al principio parece que no le agrada, así que se toma unos segundos para observar la harina; la toca con sus manos como queriendo saber qué sucede y al hacerlo dice varias veces: " $\mathrm{mmm}$ aaaa ma ma ma". La niña ya no sólo la toca con sus manos, sino que comienza a gatear sobre la harina, la esparce un poco y mueve una de sus manos mostrando un gran placer en lo que hace.

Finalmente, Carlos se acuesta sobre la harina y, con su cuerpo totalmente extendido, esparce la harina con sus brazos una y otra vez. El gozo en esta acción es evidente. Después de un tiempo, se sienta, observa detalladamente la harina, balbucea y parece hablarle mientras la contempla y la prueba, luego toca sus piernas llenas de harina y se observa a sí mismo.

Estás tres experiencias dejan ver lo placentero que resulta para los bebés este proceso de exploración, en el que el cuerpo es todo un lenguaje con el cual pueden comunicarse con el objeto. En las acciones que desarrollan una y otra vez, descubren con sus sentidos ciertos fenómenos que son interesantes y que aunque no son propiamente juego, pueden terminar en ello.

Al respecto, Bruner (1983) hace referencia a tres de las características del juego, a saber:

1. El juego es en sí mismo un motivo de exploración.
2. Es una actividad para uno mismo y no para los otros.

3. Es un medio para la invención. (p. 164)

Este autor reconoce que el juego y la exploración están íntimamente relacionados y que no pueden existir el uno sin el otro, pues se complementan. Quizás sea ésta la manera de conceptualizar el juego que podría relacionarse con aquella creencia de las maestras que valoran el juego y la exploración en el mismo nivel. No obstante, si la exploración no está acompañada de la observación de la maestra, de sus preguntas y propuestas, el acto de explorar se agota en la manipulación y no trasciende al juego en el que el niño responde a preguntas como ¿de qué manera puedo hacer uso de este objeto de maneras diferentes? Por tanto, es posible afirmar que la creencia de las maestras respecto a la equivalencia entre juego y exploración. tiene un fundamento psicológico. Sin embargo, es importante hacer énfasis en que no toda exploración puede convertirse en juego.

\section{Una experiencia fascinante con el espejo}

El espejo es un objeto imprescindible en el aula de los bebés, pues apoya el proceso de construcción del "yo". Lacan (1966) nombra a esta fase del desarrollo infantil como "el estadio del espejo", un proceso en el cual el niño y la niña de los 6 a los 18 meses de edad descubre la imagen global de su cuerpo a través de la imagen especular. Para él, antes de que ocurra este fenómeno, el cuerpo no es percibido más que como una serie de sensaciones fragmentadas; pero al ver su imagen en el espejo, el niño comienza la adquisición de la noción global de su cuerpo.

El estadio del espejo es un concepto psicoanalítico que da cuenta del nacimiento de la identidad, en la cual lo más importante es que el sujeto, a través de la mirada, reconozca la imagen especular de su cuerpo.

A partir de las siguientes situaciones, se ilustra brevemente la importancia de esta fase.

La primera se suscita cuando Susana sale gateando por las colchonetas, después de terminar un masaje que le hacía su maestra. Sin pensarlo mucho, se acerca a un espejo que acaba de poner en posición diagonal la maestra y comienza a contemplar su imagen reflejada en el espejo sin acercarse mucho. Después de unos instantes, se aproxima más a su imagen proyectada, extiende su mano derecha y toca el rostro que aparece en el reflejo; cada vez se acerca más, se pone de pie y observa el reflejo de sus pies, luego observa su rostro, se agacha y mira su pecho y su mano, que pasa por el espejo como queriendo tocar a quien está 
del otro lado, como queriendo invitarlo a jugar. cuando los bebés tocan la imagen del espejo, parece como si se hubiesen encontrado con otros niños a quienes saludan, parece que aún no se reconocen a sí mismos en el reflejo.

Levin, también con un enfoque psicoanalítico (2002), expresa que:

Será a partir de este jugar frente al espejo (juegos que incluyen gesticulaciones, verbalizaciones, gestos, canciones, "morisquetas y piruetas") que se repiten en un período extenso en el tiempo de la infancia, que el niño podrá aprehender su imagen en movimiento y no confundirla con su doble especular. (p 84)

La segunda situación comienza cuando la maestra que se encuentra cerca al espejo, decide tomar a Juan que está muy cerca de ella, lo desviste, lo acerca al espejo y lo voltea hacia un lado de tal manera que él queda acostado de frente al espejo, una vez lo ha acomodado le dice: "mira ¿quién está ahí?"

Mientras el bebé contempla su imagen, la maestra le pide a su compañera un poco de aceite para masajearlo, y comienza por la espalda y el abdomen. Es evidente que él disfruta de estas caricias en su cuerpo y por ello permanece muy quieto $\mathrm{y}$, además, concentrado en su reflejo, al tiempo que la maestra le dice: “¿ahhh quién será?"

José se interesa por lo que sucede con su compañero y se apresura gateando hacia el espejo, y con él, Samuel, Susana y Sergio. Al llegar, José observa su imagen y la de su compañero, quien se encuentra acostado recibiendo un masaje muy relajante y quien al ver la cercanía de José, extiende su brazo derecho y le toca su rostro reflejado en el espejo. Cuando lo hace, el bebé decide sentarse sin quitar su atención de él; al parecer, se inicia un diálogo de miradas, todo desde las imágenes producidas en el espejo.

Por último, Juan, quien queda frente al espejo junto a Samuel, que acaba de llegar, observa primero su imagen y luego la de su compañero, la toca y observa el recorrido que hace una de sus manos cuando toca el espejo, pasa un tiempo y él continua mirándose a sí mismo.

Entre tanto, Samuel se arrodilla, se apoya en el espejo, observa su rostro, sus manos y sus muslos, decide ponerse de pie y al ver que su imagen desaparece, porque el espejo no lo cubre todo, se busca hasta que vuelve a aparecer y se queda un segundo quieto como pensando en lo ocurrido. Después decide flexionar y estirar las rodillas y hacer este movimiento repetidamente durante unos segundos, mientras observa sin quitar sus manos del espejo y sin dejar de mirar su rostro.

Levin (2002) manifiesta que:

En estos juegos posturales de descubrimientos y conquistas imaginarias frente al espejo, los niños suelen llegar a con-tactar esa superficie plana del espejo, en el afán de tomar la imagen, de este modo colocan diferentes partes de su cuerpo como por ejemplo su boca, sus ojos, sus manos, su lengua, en con-tacto con las partes simétricas de la imagen; aunque esa superficie plana y fría del espejo no deja de separarlos, provocando nuevamente la repetición del juego de tocar- no tocar, aparecerdesaparecer, acercarse-alejarse. (p.84)

Las tres situaciones evidencian la exploración y el juego de los bebés con su reflejo, la imagen de sí mismos y de sus compañeros, que les produce curiosidad, interés y preguntas sobre él mismo y sobre los demás.

En Reggio Emilia el espejo es muy importante porque:

Permite el control de sí mismo en movimiento, el de los compañeros junto al propio...que puede sugerir o permitir, si el adulto lo propone, construcciones simétricas cuyo producto final es el conjunto real (las construcciones) o el simulado (el reflejo). (p 64)

Ahora bien, en cuanto a las creencias de las maestras, se pueden hacer algunas precisiones. Por un lado, las experiencias que han tenido con sus hijos en cuanto a los juegos con el espejo se convierten en la piedra angular para diseñar las propuestas que ofrecen a niños y niñas. Esto se inspira, desde luego, en la filosofía y metodología de Reggio, que les ha ayudado a comprender la importancia del espejo en la construcción de la imagen corporal y de la identidad. Por otro lado, el espejo por sí solo no lograría estructurar la complejidad de este proceso; el otro que se refleja en este es importante en esta construcción, pues le ayuda al niño a comprender su imagen global, reflejada en el espejo.

Es decir, el acompañamiento en este tipo de juegos es crucial, porque de lo contrario este objeto pasaría a ser un sin sentido en la vida de niños y niñas.

El panorama expuesto refleja que las maestras de la institución uno, aunque diseñan las mismas experien- 
cias para todos los niños de un nivel, tienen muy claro que cada quien asume de manera diferente su práctica de acuerdo con su contexto, historia e interacciones. Ello implica que la maestra reconoce que cada bebé es diferente, como diferente es la manera como se aproximan a las experiencias que ella le propone. De esta manera, aunque en las políticas educativas la inclusión social parece un problema de cobertura exclusivamente, y por ende de espacio, estas maestras evidencias que el problema reside en gran parte en la manera en como asumimos al otro.

\section{Referencias}

Bolívar, A. (2002). ¿De nobis ipsis silemus?: Epistemología de la investigación biográfico-narrativa en educación. Revista Electrónica de Investigación Educativa, 4(1). Recuperado de URL: http://redie.uabc.uabc.mx/vol4no1/contenido-bolivar.html [Consultado el 20 de marzo de 2011].

Bruner, J. (1984). Juego pensamiento y lenguaje. En Linaza comp. Acción pensamiento y lenguaje. Madrid: Alianza.
Cano, M.I y Lledó A (1997). Espacio, Comunicación y Aprendizaje. Edición Díada, Sevilla.

Garvey, C. (1978/1983). El Juego Infantil. Madrid: Morata, tercera edición.

Glanzer, M. (2000). El juego en la niñez. Buenos Aires: Aique.

Lacan, J. (1966). El estadio del espejo como formador de la función del yo(je) tal como se nos revela en la experiencia psicoanalítica. Escritos, volumen 1.

Levin, E. (2002). La infancia en escena: constitución del sujeto y desarrollo psicomotor, Buenos Aires: Nueva visión.

Sarlé, P. (2006). Enseñar el juego y jugar la enseñanza. Buenos Aires: Paidós.

Vygotsky, L.S. (1933). El desarrollo de los procesos Psicológicos superiores. Barcelona: Grijalbo, 1979, pág. 154. 